\title{
Research on Current Situation and Countermeasures of Multimodal Transport in Shandong Province
}

\author{
Chang XU ${ }^{1}$, Xiuling CHEN and Xinjian ZHU \\ Shandong Transportation Research Institute, Jinan, China
}

\begin{abstract}
The development of multimodal transport has become an important gripper to promote logistics cost reduction and efficiency enhancement, improve the quality of modern comprehensive transportation services, and build a green transportation system, which is of great significance for building powerful transportation in Shandong Province. In recent years, the transportation industry in Shandong Province has developed rapidly, but there are still certain shortcomings in the development of multimodal transportation. This article is based on the status of the development of multimodal transport in Shandong Province, conducted an indepth analysis and research on the issues restricting the rapid development of multimodal transport in Shandong Province, and in-depth analysis of the new situation and new challenges faced by the development of multimodal transport in Shandong Province. Thus, countermeasures and suggestions are put forward for infrastructure construction, innovative service models, improving the level of informatization, and cultivating market systems.
\end{abstract}

Keywords. Multimodal transport, green transportation system, infrastructure construction

\section{Introduction}

Multimodal transport is the basic support for building a modern logistics system, it is an important means for China to reduce economic and social operating costs [1], promote international and domestic dual cycles, and build a global industrial chain of advanced manufacturing. Simultaneously, it is an important gripper for adjusting the transportation structure, improving the efficiency of resource utilization, and improving the logistics benefits of the whole society [2-3]. It has a positive role in promoting energy conservation, environmental protection, quality improvement and efficiency improvement in the transportation industry. Shandong Province clearly proposed to promote the construction of an integrated multimodal transportation system in the "Implementation Plan for the Special Action for Cost Reduction and Efficiency Increase in the Logistics Industry of Shandong Province". Shandong Provincial Department of Transportation and 24 provincial departments jointly formulated the "Implementation Plan for Implementing the Notification of the Ministry of Transport and other 18 Departments to Promote the Development of Multimodal Transport in Our Province", confirmed to build "Reasonable layout, advanced technology, complete facilities,

${ }^{1}$ Corresponding Author, Chang XU, Shandong Transportation Research Institute, Jinan, China; Email: 512346679@qq.com. 
convenient and efficient, green and environmental protection, safe and orderly" multimodal transportation system as the phased goal.

However, insufficient railway capacity in Shandong Province, unsmooth infrastructure connections, and lack of a unified multimodal transport management platform still restrict the rapid development of Shandong's multimodal transport ${ }^{[4-6]}$. Therefore, in-depth analysis of the restrictive factors of the development of multimodal transport in Shandong Province, formulate the development ideas and countermeasures of multimodal transport in Shandong Province, it is of certain significance to promote the efficient and sustainable development of multimodal transport in Shandong Province.

\section{Overview of the Development of Multimodal Transport in Shandong Province}

Relying on the large logistics channels inside and outside, Shandong Province focuses on promoting the construction of infrastructure such as road-rail combined transportation, iron-water combined transportation, land-air combined transportation. Speeding up the promotion of road drop-and-hook transportation, we are committed to accelerating the development of multimodal drop and pull, enterprise alliances, car-free transportation and drop and pull transportation. Supporting the construction of multimodal transport public information platform, promoting the exchange and sharing of multimodal transport information, and strengthening the unified connection of facility standards, delivery vehicles, management rules, information systems, etc., thereby improving the efficiency of trunk line transportation and the level of integrated services. Through the development of demonstration projects such as multimodal transport and containerized iron-water transport, a provincial-level multimodal transport demonstration center will be built.

\subsection{Speeding up the Construction of Multimodal Transport Hubs}

Shandong Province's multimodal transport hub facilities have begun to take shape, Multimodal transport logistics parks such as the Dongjia Town Railway Logistics Park of Jinan Railway and the Multimodal Transport Center of Shanghai Hexi District have been built. Multimodal logistics parks are mainly concentrated in Qingdao, Linyi, Jinan, Weifang, Rizhao, Taian, Weihai and other cities, by the end of 2020, there are 48 largescale multimodal transport logistics parks in Shandong Province. Among them, there are 33 road-rail combined transport parks, 11 road-rail water combined transport parks, 3 sea-rail combined transport parks, and 1 land-air combined transport logistics park (figure 1).

\subsection{Optimization and Innovation of Multimodal Transport Mode}

Shandong Province's multimodal transport model continues to optimize and innovate, it has formed "Gum Yellow Small Operation", "China-Korea Land-Sea Combined Transport", "China-Europe and Central Asia International Freight Train", "Lu-Liao RoRo Transport", "Zaozhuang Inland Port", "Truck Flight" and other new features with Shandong characteristics. Model, and has been promoted and applied nationwide. By the end of 2020, Shandong Province has successively opened six passages from Weihai to Incheon, Qingdao to Incheon, Rizhao to Pingze, Longan to Pingze, Shidao to Gunsan, 
and Yantai to Pingze. China-South Korea land-sea combined transport completed a total of 1.65 billion US dollars in trade volume.

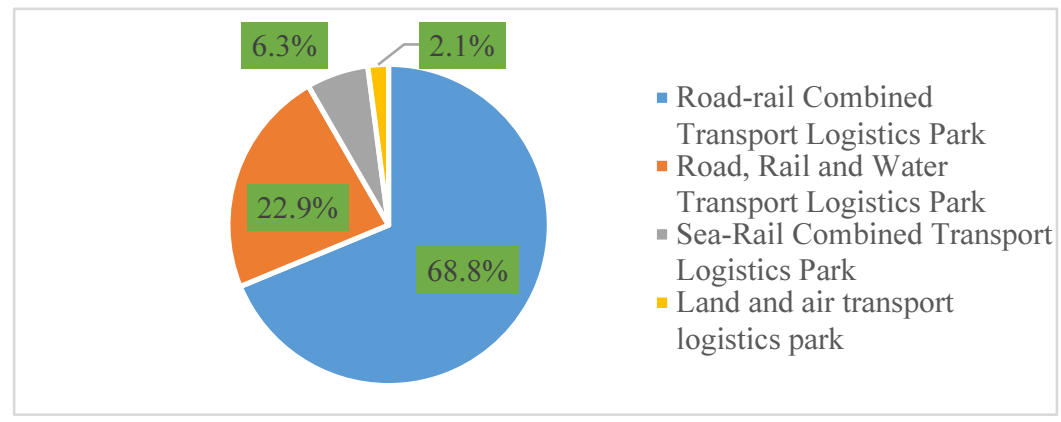

Figure 1. Distribution of different types of large-scale multimodal transport logistics parks.

\subsection{Intermodal Scale Steady Improvement}

Shandong Province is actively developing multimodal transport business, with rapid growth of sea-rail combined transport and China-Europe freight trains. By the end of 2020 , the provincial multimodal transport project library has 4 national and 33 provincial demonstration projects, with 60 participating enterprises. In 2020, the province's railway container multimodal transport volume was 40.88 million tons, a year-on-year increase of $38.1 \%$ and an increase of $180 \%$ over 2017 (figure 2); 1.65 million TEUs of operation boxes will be completed, a year-on-year increase of $19 \%$; The number of Eurasian trains has exploded. In 2016, the province opened 279 Eurasian trains. In 2020, the number of two-way Eurasian trains in the province reached 1,506, ranking first in the country, with an average annual growth rate of $52.4 \%$.

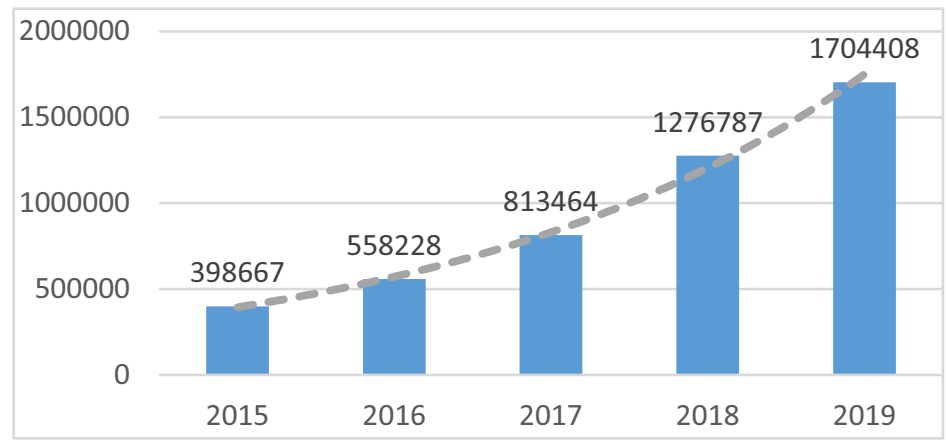

Figure 2. Shandong railway container multimodal transport volume during 2015-2019.

\section{Analysis of Existing Problems}

Under the new situation, Shandong Province's multimodal transport is facing a transitional period from quantitative extensional growth to quality connotative development, The contradiction between the urgent demand for multimodal transport 
and the lagging supply capacity has become increasingly prominent [7-8]. The main problems are as follows:

\subsection{Integrated Traffic Management Systems Need Improvement}

For a long time, transportation has been managed by departments in accordance with the mode of transportation, and there has been a lack of effective cooperation and coordination between departments. The current transportation demand and transportation capacity configuration lack the overall layout of the management unit, insufficient connection between transportation methods, logistics parks, distribution centers, and the transportation nodes of multimodal transportation cannot be effectively linked, unable to form a regional and large-scale multimodal transport network.

\subsection{Insufficient Railway Capacity Is Widespread}

Shandong Province is actively developing multimodal transportation, but due to the lack of overall planning, the macro planning is unreasonable, and there are repeated and staggered train routes, which gradually formed a situation of overcapacity in transportation and "cars but no goods". In the context of the current development of "railway transfer", most international trains currently have no source of goods for the return journey. At the same time, railway container transportation clearly stipulates those 104 kinds of goods can be packed in boxes, and other imported goods in containers are not allowed to be shipped, which affects the organization of sources of goods [9].

\subsection{Poor Connectivity of Multimodal Transport Infrastructure}

"Bad connection" or "neighbor but not connection" between important transportation hubs, and between passages and important port hubs, especially the ineffective connection between railways and other transportation resources, has become an important factor restricting the development of multimodal transportation [10]. Most railway stations and supervised operation sites in various cities in the province are not in the same place, and goods need to circulate back and forth between the two places, which increases the logistics cost of enterprises.

\section{Analysis on the Development Countermeasures of Multimodal Transport in Shandong Province}

\subsection{Improving the Multimodal Transport Infrastructure}

\subsubsection{Improving the Supply Capacity of Railway Transport Capacity}

Push forward the construction of dedicated railway freight lines and express lines that connect to logistics parks and connect cargo sources and ports, and rationally plan to increase freight trains; accelerate the construction of the collecting and discharging port railway freight system in Qingdao, Yantai, Rizhao, and Weihai, and improve the seamless connection capacity and capacity matching of railways and ports (figure 3 ). 


\subsubsection{Layout Optimization of Multimodal Transportation Channels and Hubs}

Promoting the construction of the infrastructure of the four major logistics channels in the province, including the inland bridge logistics channel and the Qingyin logistics channel focuses on building a multimodal transport gathering area around Jinan and Yanqinglin multimodal transport gathering belt and encourages railway, port, shipping and other enterprises to cooperate in the construction of inland dry ports.

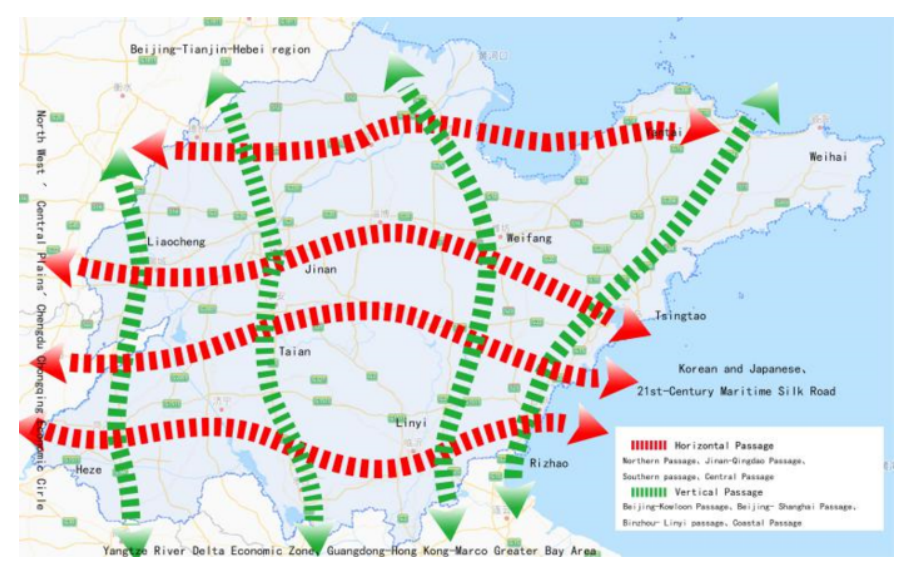

Figure 3. Domestic multimodal transport logistics channel in Shandong Province.

\subsection{Innovative Multimodal Transport Service Model}

\subsubsection{Vigorously Promoting the Combined Transportation of Iron and Water in Containers}

Promoting the formation of iron-water intermodal transportation hubs with Qingdao, Yantai, Rizhao, etc. as the core, continue to play the role of container intermodal transportation channels from Qingdao to Zhengzhou and areas along the Longhai line, it increases the proportion of intermodal transportation of iron and water, and optimize the efficient connection with Europe and Asia.

\subsubsection{Promoting the Combined Transportation of Bulk Dry and Bulk Cargo with Water and Iron}

Strengthen the railway connection between port enterprises and large enterprises such as steel and electric power, and optimize the organization of combined transportation of iron and water, and promote the transfer of bulk cargo transportation from roads to railways.

\subsection{Improve the Level of Multimodal Transport Informatization}

\subsubsection{Develop a Comprehensive Information Platform for Multimodal Transport}

Promoting the province's ports, railways, highways, aviation, shipping companies and multimodal transport management departments to jointly establish a multimodal transport information system, and in-depth analysis of multimodal transport information needs and business needs, then develop functions such as multimodal transport route 
planning, inquiry and capacity matching across transport modes, and build a platform covering the entire chain of multimodal transport.

\subsubsection{Promote Multimodal Transport Information Sharing}

Promoting the disclosure of government affairs information, promote information sharing among various government departments, innovate the government-enterprise cooperation model, relying on the existing information management system, and promote the province's ports, railways, highways, aviation, shipping companies and multimodal transport management departments to jointly establish a multimodal transport information system.

\subsection{Cultivate a Multimodal Transport Market System}

\subsubsection{Cultivate Multimodal Transport Operation Enterprises}

Actively cultivate multimodal transport enterprises that have the ability to organize freight transportation across modes of transportation and assume full responsibility for the entire process, and guide enterprises to establish a service method of "one-time entrustment" throughout the entire process, "one order to the end" of the waybill, and "one-time collection" for settlement, support new Internet service models such as electronic waybill and online settlement for enterprises.

\subsubsection{Establish a Credit Management System}

Relying on websites such as "Credit Shandong" and "Shandong Market Subject Credit Information Publicity System", continuously improve the multimodal transport credit system. Based on various market operators of multimodal transport, gradually establish a credit evaluation system for multimodal transport operations, and establish a multimodal transport credit information management platform.

\subsection{Expand Domestic and International Multimodal Transport Markets}

\subsubsection{Improve the Business Environment at Shandong Port}

Give full play to the advantages of ports close to Japan and South Korea, support the free replacement of transit cargo sea containers and railway boxes, promote the development of domestic sea-rail combined transport import and export and transit business to Japan and South Korea, and build Shandong Port into a major maritime entry and exit port along the Yellow River.

\subsubsection{Establish an International Transportation Exchange and Cooperation Mechanism}

Actively build "economic and trade cooperation industrial parks" with countries along the "The Belt and Road Initiative", establish a complete service supporting system, and promote international trade and logistics to connect east to west. Build a regional comprehensive bonded logistics distribution center, support the center to expand the transit transportation business between Central Asia and Japan and South Korea. 


\section{Conclusion}

Shandong Province is one of the largest transportation Province in China. The development of multimodal transport is the only way to realize the strategic measures of strong transportation Province, carbon peak and carbon neutralization. Through the research on the current situation of multimodal transport, the existing problems are analyzed, and the Countermeasures of information, market system and equipment are put forward from the aspects of infrastructure, service mode and service mode, It lays a solid foundation for the stage differences of multimodal transport development strategy in Shandong Province.

\section{References}

[1] General Administration of Quality Supervision, Inspection and Quarantine, National Standardization Administration 2009 Multimodal Transport Service Quality Requirements GB/T24360-2009.

[2] Ministry of Transport 2016 Notice on Further Encouraging Multimodal Transport.

[3] Zhang B 2008 Problems and countermeasures of China's international container multimodal transport Traffic Enterprise Management 23 (1) 59-60.

[4] Chen G Y, et al. 2020 Suggestions for improving the land-sea linkage ability of "One Belt and One Road" in Shandong Province Water Transportation Management 42 (1) 21-22+29.

[5] Dong F 2021 Research on the development trend of China's multimodal transport during the 14th Five Year Plan period China Economic and trade guide China Economic \& Trade Herald 2021 (14) 48-50. (in Chinese)

[6] Zhuang H 2021 Research on the development strategy of railway multimodal transport Railway Transport and Economy 43 (2) 1-6.

[7] Han C 2020 Research on the development, construction and implementation path of eurasian express train under the modern supply chain-Taking Shandong "Qilu" as an example Journal of Southwest Jiaotong University (Social Science Edition) 21 (5) 124-130.

[8] Liang X K 2016 Research on Optimization of Railway Container Multimodal Transport Scheme with Time Window (Chengdu: Southwest Jiaotong University).

[9] Wang X 2016 Enlightenment and thoughts on the development of container multimodal transport in the United States Railway Transport and Economy (5) 91-94.

[10] Xie S X and Sun X M 2017 Research on the development model and strategy of logistics multimodal transport under the "One Belt One Road" strategy Railway Purchasing and Logistics 12 (01) 51-54. 